prospectively. An independent Gastrointestinal Events Committee (GEC) reviewed all data in a blinded fashion. Events were categorised as UGI ulcer complications (perforations, gastric outlet obstruction, bleeding) or symptomatic UGI ulcerations (predefined as in CLASS). A total of 144 cases were reviewed and adjudicated by the GEC.

Results See Table 1.

\begin{tabular}{lllll} 
Abstract THU0182 Table 1 & & & & \\
\hline & Celecoxib & NSAIDs & Odds & $95 \% \mathrm{Cl}$ \\
& $\mathbf{N}=\mathbf{8 8 0 0}$ & $\mathbf{N}=4934$ & Ratio & \\
\hline Exposure (pt-yr) & 1721.2 & 857.9 & & \\
Ulcer Complications (annualised rate) & $2 / 1721.2$ & $7 / 857.9$ & 7.02 & $1.46 \llbracket 33.80$ \\
& $(0.1 \%)$ & $(0.8 \%)^{*}$ & & \\
Ulcer Complications + Symptomatic & $18 / 1721.2$ & $21 / 857.9$ & 2.01 & $1.04 \llbracket 3.86$ \\
Ulcers (annualised rate) & $(1.0 \%)$ & $(2.1 \%)^{*}$ & & \\
\hline${ }^{*} \mathrm{p}<0.05$ vs celecoxib. & & & &
\end{tabular}

Conclusion These data confirm CLASS results that celecoxib is associated with significantly fewer ulcer complications and symptomatic UGI ulcerations than conventional NSAIDs. The differences in event rates between SUCCESS and CLASS may relate to regional differences in surveillance or clinical practice.

Sponsored by Pharmacia Corporation and Pfizer, Inc.

\section{THU0183 SIGNIFICANTLY IMPROVED UPPER GASTROINTESTINAL (UGI) TOLERABILITY WITH CELECOXIB, A COX-2 SPECIFIC INHIBITOR, COMPARED WITH CONVENTIONAL NSAIDS. THE SUCCESS I TRIAL}

${ }^{1} \mathrm{JL}$ Goldstein, ${ }^{2} \mathrm{~N}$ Agrawal, ${ }^{3} \mathrm{G}$ Eisen, ${ }^{4} \mathrm{~W}$ Stenson, ${ }^{5} \mathrm{AE}$ Bello, ${ }^{5} \mathrm{JG}$ Fort, ${ }^{5} \mathrm{SP}$ Boots. ${ }^{1}$ Department of Medicine, University of Illinois at Chicago, Chicago; ${ }^{2}$ Department of Medicine, Duke University Medical Center, Durham; ${ }^{3}$ Department of Medicine, Vanderbilt University Medical Center, Nashville; ${ }^{4}$ Department of Medicine, Washington University Medical School, St Louis; ${ }^{5}$ Research and Development, Pharmacia Corporation, Skokie, USA

\subsection{6/annrheumdis-2001.1085}

Background The Celecoxib Long-term Arthritis Safety Study (CLASS), a prospective outcomes study conducted in North America, demonstrated a significant reduction in UGI ulcer complications and improved tolerability.

Objectives To extend our understanding of the UGI safety advantages of celecoxib over conventional nonsteroidal antiinflammatory drugs (NSAIDs), in day-to-day practice, a naturalistic study was conducted worldwide.

Methods SUCCESS I, a large, 12-week, multinational, doubleblind, randomised trial in 13,274 osteoarthritis patients, was conducted in 39 countries. There were 6547 patients from Europe/Africa, 2756 from North America, 2889 from Latin America, and 1082 from Asia/Pacific. Celecoxib $200 \mathrm{mg} / \mathrm{d}$ ( $\mathrm{n}=$ $4421)$ and $400 \mathrm{mg} / \mathrm{d}(\mathrm{n}=4429)$ was compared with naproxen $1000 \mathrm{mg} / \mathrm{d}(\mathrm{n}=914)$ and diclofenac $100 \mathrm{mg} / \mathrm{d}(\mathrm{n}=3510)$ with regard to GI tolerability.

Results The frequency of all reported GI adverse events (AEs), the three most frequently reported UGI AEs, and withdrawals due to GI AEs are shown in the Table 1.

Abstract THU0183 Table 1
\begin{tabular}{clll}
\hline NSAIDs & Celecoxib & \% Reduction & p Value \\
$(\mathrm{N}=4394)$ & $(\mathrm{N}=8800)$ & & \\
\hline
\end{tabular}

\begin{tabular}{lllll} 
All GI AEs & $21.0 \%$ & $16.7 \%$ & $20.4 \%$ & $<0.001$ \\
UGI AEs & $15.6 \%$ & $11.9 \%$ & $23.7 \%$ & $<0.001$ \\
Abdominal pain & $6.2 \%$ & $4.8 \%$ & $22.5 \%$ & $<0.001$ \\
Dyspepsia & $5.9 \%$ & $4.8 \%$ & $18.6 \%$ & $<0.008$ \\
Nausea & $3.4 \%$ & $2.4 \%$ & $29.4 \%$ & $<0.001$ \\
Withdrawals due to GI AE & $6.8 \%$ & $5.2 \%$ & $23.5 \%$ & $<0.001$ \\
\hline
\end{tabular}

Conclusion UGI symptoms, more commonly associated with NSAID use, were consistently and significantly lower with celecoxib. The percent reduction ranged from $18.6 \%$ to $29.4 \%$. These data confirm the superior GI tolerability of celecoxib vs conventional NSAIDs and establish that this difference is clinically meaningful in terms of discontinuation of therapy for such symptoms. Sponsored by Pharmacia Corporation and Pfizer, Inc.

\section{THU0184 POLYMORPHONUCLEAR CELL COUNTS (PMN) EFFECTIVELY PREDICT MORTALITY IN RHEUMATOID ARTHRITIS (RA) PATIENTS FOLLOWED FOR UP TO 20 YEARS}

${ }^{1} \mathrm{~F}$ Wolfe, ${ }^{2} \mathrm{HK}$ Choi. ${ }^{1}$ National Data Bank for Rheumatic Diseases, Arthritis Research Center Foundation, Wichita, USA; ${ }^{2}$ Rheumatology Unit, Harvard Medical School, Boston, USA

\subsection{6/annrheumdis-2001.1086}

Background Mortality is increased in rheumatoid arthritis (RA), and this increase is related to disease severity markers, disease activity and psychosocial factors. It has been previously reported that white cell counts (WBC) predict total joint replacement in $\mathrm{RA},{ }^{1}$ and $\mathrm{WBC}$ levels are associated with cardiovascular mortality in non-RA populations. ${ }^{2}$ The effect of WBC, especially PMN, on mortality has not been studied in RA, but might be clinically important.

Objectives To investigate the relation between PMN and mortality in RA.

Methods During a 20-year period ending in 2000, 1500 consecutive RA patients had 21,581 clinic visits at which $18,850 \mathrm{WBC}$ tests were performed. 544 patients died. The predictability for mortality of PMN and other variables obtained 1) during the first 2 years of follow-up and 2) over the entire course of RA was examined using Cox regression models (Cox). To assess the impact of covariates on the predictability of PMN, we controlled for RF, ESR, age, disease duration, sex, HAQ, and prednisone use in multivariate Cox models. Generalised estimating equations (GEE) were used to describe the relation of PMN to other variables.

Results The mean (SD) of WBC and PMN was 8.0 (2.8) and 6.0 (2.5), respectively. Total PMN but not lymphocyte counts predicted mortality ( $p<0.05$ and $p=0.522$, respectively). The mean PMN values in its quartiles were 3.5, 4.9, 6.2 and 9.0. Over the entire course of RA the hazard ratios (HR) for mortality compared with Q1 were Q2 1.5 (1.1,1.9), Q3 $1.9(1.4,2.5)$ and Q4 $2.8(2.2,3.7)$. By contrast, the HR for rheumatoid factor positivity (RF) was $1.6(1.3,2.1)$. HR for PMN during the 1 st 2 years of follow-up were Q2 $1.5(1.1,1.9)$, Q3 $2.0(1.6,2.6)$ and Q4 $2.4(1.8,3.1)$. For those in Q1-Q4 during the 1st 2 years, the predicted $25 \%$ time to death was $11.7,8.8,7.2$ and 4.6 years, respectively. To assess the effect of covariates on the predictive ability of PMN, covariates that included RF, ESR, age, disease duration, sex, HAQ, and prednisone use were added to the 2-year and lifetime PH models. PMN remained significant in the multivariate Cox models, and was a stronger predictor of 
mortality than RF or ESR. In GEE analyses, the strongest predictor of PMN was, by far, the use of prednisone, with users having $1.8(1.6,2.0)$ thousand cells increase compared to non-users. Weaker predictors of PMN included sex, HAQ, ESR, RF, disease duration, but not age.

Conclusion Total PMN predicts mortality in RA as effectively as $\mathrm{RF}$, and the predictability is robust to duration of disease as well as to fixed and time-dependent disease severity covariates. This simple test appears to have been overlooked, but adds significantly to our ability to predict mortality in RA. Corticosteroids are the strongest influence on PMN among RA patients, and might be an important factor in mortality increase in RA. Treatment related PMN reduction that occurs in clinical trials of biologic agents may be a marker for increased survival, and is a candidate variable for measurement of pharmaco-economic benefit.

\section{REFERENCES}

1 Arthritis Rheum. 1998;41(6):1072-82

2 N Engl J Med. 2000;343(16):1148-55

\section{THU0185 RELIABILITY OF RA MRI SCORING}

${ }^{1} \mathrm{MN}$ Lassere, ${ }^{2} \mathrm{~F}$ McQueen, ${ }^{3} \mathrm{M}$ Ostergaard, ${ }^{4} \mathrm{P}$ Conaghan, ${ }^{1} \mathrm{R}$ Shnier, ${ }^{5} \mathrm{C}$ Peterfy, ${ }^{3} \mathrm{M}$ Klarlund, ${ }^{2} \mathrm{~N}$ Stewart, ${ }^{4} \mathrm{P} \mathrm{O}^{\prime}$ Connor, ${ }^{1} \mathrm{P}$ Bird, ${ }^{1} \mathrm{~J}$ Edmonds, ${ }^{4} \mathrm{P}$ Emery, ${ }^{6} \mathrm{H}$ Genant. ${ }^{1}$ Department of Rheumatology, St. George Hospital, Sydney, Australia; ${ }^{2}$ Department of Molecular Medicine, Auckland, New Zealand; ${ }^{3}$ Department of Rheumatology, University of Copenhagen, Copenhagen, Denmark; ${ }^{4}$ Rheumatology Research Unit, University of Leeds, Leeds, UK; ${ }^{5}$ Synarc Inc., San Francisco, USA; ${ }^{6}$ Department of Radiology, University of California, San Francisco, USA

\subsection{6/annrheumdis-2001.1087}

Background At OMERACT5 recommendations were developed for acquisitions/scoring of MRI synovitis/bone destruction of hand/wrist in RA: OM5 RA MRI Score (Om5 RAMRIS). ${ }^{1}$ These were based on results of a multicentre inter-reader agreement studies of two earlier MRI scoring methods, developed at EULAR 1999 and ACR 1999. ${ }^{2}$

Objectives Determine whether reader calibration, standardisation of imaging protocols and more precise definitions of lesions improved inter-reader agreement of MRI scoring.

Methods MRIs (1.5T, cor and axial T1\& T2, FS, iv Gd) of wrist

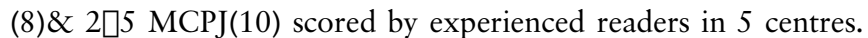
Synovitis determined by Gd enhancement in synovial compartment by 2 methods: global score $(0 \square 3)$ (wrist 3 sites, MCPJ 4 sites) and direct measure $(\mathrm{mm})$ of maximal thickness of enhancing tissue (wrist 4 sites, MCPJ 2 sites). Bone erosion (wrist 15 sites, MCPJ 8 sites) was a bone defect with sharp margins, with a cortical break. Bone defect and bone oedema also defined. All measured $0 \square 10$ by volume of defect as proportion of assessed bone volume by $10 \%$ increments judged on all images.

Results Reliability for most sites for all lesions was good. Poor intraclass correlation coefficients for bone defect (but excellent agreement) were due to predominance of zero scores. Table 1 shows results of summated scores). Om5 RAMRIS performed better than our previous scoring methods.

\begin{tabular}{lllll}
\multicolumn{5}{l}{ Abstract THU0185 Table 1} \\
\hline & MCPJ & MCPJ & Wrist & Wrist \\
& ICC & \% agree 1 interval & ICC & \% agree 1 interval \\
\hline Synovitis Glob & 0.77 & 59 & 0.71 & 34 \\
Synovitis mm & 0.58 & 23 & 0.56 & 55 \\
BE & 0.46 & 37 & 0.68 & 11
\end{tabular}

\begin{tabular}{llrll} 
BD & 0.12 & 90 & 0.13 & 70 \\
BO & 0.60 & 22 & 0.84 & 25 \\
\hline Reliability of inter-reader MRI scores.
\end{tabular}

Conclusion We found Om5 RAMRIS has acceptable inter-reader reliability. Whether it can be further improved and degree to which it's sensitive to change will need to be determined by its performance in longitudinal/intervention studies.

\section{REFERENCES}

1 Conaghan, et al. J Rheum, in press

2 Ostergaard, et al. J Rheum, in press

\section{THU0186 THE EVALUATION OF THE RISK FACTORS FOR GENERALISED OSTEOPOROSIS IN PATIENTS WITH RHEUMATOID ARTHRITIS}

Ü Bingöl, L Altan, E Dinçsahin, M Yurtkuran. Physical Therapy and Rehabilitation, Uludag University, Medical Faculty, Bursa, Turkey

\subsection{6/annrheumdis-2001.1088}

Background In patients with rheumatoid arthritis (RA), the frequency of generalised osteoporosis is increased. The factors related to the disease like duration, functional capacity, medical treatment (corticosteroid, nonsteroidal drugs, methotrexate) and disease activation (C-reactive protein, erythrocyte sedimentation rate) are present among the probable factors which increase the risk of generalised osteoporosis such as the general factors like sex, age and menapausal status.

Objectives The effects of the general risk factors and the risk factors related to the disease on the formation of osteoporosis were assessed statistically with the ordinal logistic regression test. Methods The bone mass of 36 patients with RA (between the ages of $25-75$ and duration of disease $0,25-43$ years ? 32 female, 4 male) were evaluated with calcaneal ultrasound.

Results It was estimated that the risk of osteoporosis is increased 7.44 times in patients using nonsteroidal anti-inflammatory drugs (NSAID) compared with those who received no NSAID treatment. $(\mathrm{P}=0.05$, Odds Ratio $=7.44,95 \%$ Confidence interval $=1-55.46$ )

Conclusion This data has shown us the importance of NSAID treatment in increasing the risk of generalised osteoporosis in RA patients.

\section{REFERENCES}

1 Laan RFJM, van Riel PLCM, van de Pute LBA. Bone mass in patients with rheumatoid arthritis. Ann Rheum Dis. 1992;51:826-32

2 Gough AKS, Lilley J, Eyre S, Holder RL, Emery P. Generalized bone loss in patients with early rheumatoid arthritis. Lancet 1994;344:23-7

3 Mellsh RWE, O'Sullivan MM, Garrahan NJ, Compston JE. Iliac crest trabeculer bone mass and structure in patients with non steroid treated rheumatoid arthritis. Ann Rheum Dis 1987:46:830-6

4 Ewans WD, Ewans C. Long term follow up of spinal trabeculer bone mineral density in women with non-steroid treated rheumatoid arthritis. Ann Rheum Dis. 1994;53:149

\section{THU0187 QUALITY OF LIFE IM RHEUMATOID ARTHRITIS: ADAPTATION OF RAQOL FOR USE IN TURKEY}

S Kutlay, D Gonul, A Kucukdeveci. Ankara University, Faculty of Medicine, Ibni Sina Hospital, Ankara, Turkey

10.1136/annrheumdis-2001.1089 